\title{
The perception of biopsychosocial impacts of COVID-19 during lockdown restrictions over time in the UK - a mixed methods study
}

\author{
Samuel Grimwood ${ }^{1}$, Kaz Stuart ${ }^{2 *}$, Ruth Browning ${ }^{2}$, Elaine Bidmead ${ }^{2}$, Thea Winn-Reed ${ }^{2}$
}

\begin{abstract}
Background: The COVID-19 pandemic has profoundly impacted the health of individuals physically, mentally, and socially. This study aims to gain a deeper understanding of this impact across the pandemic from a biopsychosocial stance.

Methods: A survey created by the research team was employed between November 2020 and February 2021 across social media, relevant organizations, and networks. The survey incorporated 5-time points across the different stages of the pandemic, covering biological, psychological, and social. There were 5 items for each survey (Very Positive affect to Very Negative affect), and analysis was undertaken using SPSS version 16. Descriptive statistics and nonparametric Friedman and Wilcoxon Tests, as well as correlations between the three domains, were implemented.

Results: This study included 164 participants $(77.0 \%$ female and $35.0 \%$ male) across 24 out of 38 counties in the UK. The impact of COVID-19 on biological domain was significant across the five data points $\times 2(4)=63.99, P<0.001$, psychological $X 2(4)=118.939, P<0.001$ and socially $X 2(4)=186.43, P<0.001$. Between the 5 data points, 4 out of 5 had a negative impact, however between the first stage of lockdown and the easing of restrictions, findings for biological $(Z=-2.35, P<0.05)$, psychological $(Z=-6.61, P<0.001)$, and socially $(Z=-8.61, P<0.001)$ were positive. Negative correlations between the three domains across the pandemic are apparent, but in later stages, the biological domain had a positive correlation $r=0.52, P<0.001$.

Conclusion: The data shows a negative impact from the self-reported perception of wellbeing from a biopsychosocial stance over time, as well as perceiving the three domains to interact negatively. To address these biopsychosocial issues, the research implies a place-based integrated recovery effort is needed, addressing biological, psychological, and social issues simultaneously. Further research should investigate biopsychosocial health among a more generalizable population.
\end{abstract}

Keywords: Biopsychosocial, COVID-19, Integrated Care, Place-Based Care, United Kingdom

\section{Background}

The COVID-19 virus impacted the UK in January 2020, leading to three national lockdowns between March 2020 and March 2021. Early efforts focused on the prevention of the transmission, treatment, and development of a vaccine. These clinical needs became more pressing as prevalence and mortality rates increased. The control measures, particularly full lockdown at home, created profound life changes for people across the UK. As time progresses, the scale, depth, and

*Correspondence: kaz.stuart@cumbria.ac.uk

${ }^{2}$ Centre for Research in Health and Society, University of Cumbria, Fuse hill Street, Carlisle, CA1 2HH, UK.

Full list of author information is available at the end of the article inequity of the impact of these changes are becoming more apparent $[1,2,3]$. The research team conducted qualitative research to explore the effects on people of COVID-19 and associated control measures throughout the first two lockdowns [4]. This provided us with a firm understanding of the impacts and highlighted that these had biological, psychological, and social elements, expressly a biopsychosocial impact. These issues have been documented in another research as a singular phenomenon, as discussed below.

George Engel originally proposed the biopsychosocial model (BPS) in order to address the shortcomings he perceived in medicine [5]. This BPS theoretical framework purports that psychological and social factors are as significant as biological influences on health and wellbeing. The BPS theory is 
grounded in general systems theory and complexity theory [6, $7,8,9,10,5,11]$. Through advocation of the BPS model, Engel $(1977 ; 1980)$ aimed to address the separation of mind and body advocated through the model's dualistic framework, the reductionistic and materialistic emphasis in medical thinking, and the influence of the observer on the observed [10,12]. The BPS model is thus presented as a more humanistic approach, considering the individual holistically both from a medical as well as cultural, social, and psychological stance $[10,12,7,13$, 14]. There is evidence of the application of the BPS model in a wide range of settings, including public health, health education, health psychology, and preventative medicine [12, 14] in addition to cardiology [15], dementia, ageing, pain [16, 17] and psychiatry [18].

Moreover, the BPS model has been used to steer understanding of previous epidemics and pandemics. Cohen (1990) [19] embraced a BPS approach in handling the human immunodeficiency virus (HIV) epidemic, which empowered those with AIDS to develop coping strategies, prevent transmission and suicide, resulting in a compassionate, optimistic, and dignified practice approach. More recently, Wainwright \& Low. [20] proposed a BPS approach to rehabilitation and recovery from COVID-19 due to the interacting medical, psychological, and social support needs required by individuals to return to a normal life.

From a biological perspective, as of May 2021, Government figures show 465,169 individuals hospitalized as a result of COVID-19 and 127,710 deaths within 28 days of a positive test for COVID-19 [21, 22]. At the same time, contracting COVID19 is also leading directly to prolonged ill-health called 'Long Covid', where symptoms exceed five weeks. Current estimates suggest that 186,000 people in private households in England live with symptoms that have persisted for between 5 and 12 weeks, with a $95 \%$ confidence interval of 153,000 to 221,000 [23]. Circuitously, other health issues have arisen as people have avoided health care and scheduled procedures were canceled. Carr et al.[24] estimate roughly 2.3 million people are currently waiting for surgical care, creating a societal health crisis. Evidence of negative psychological impact at a societal level is equally worrying. An Institute for Fiscal Studies (IFS) study found that mental health worsened by $8.1 \%$ due to the pandemic [25]. The Mental Health Foundation (2020) [26] conducted waves of research throughout the pandemic, affirming that people having suicidal thoughts and feelings within the previous two weeks increased from 8\% in April 2020 to $13 \%$ in November 2020.

In the social domain, loss of education significantly impacted children and parents. Research by the Education Endowment Foundation (2021) [27] discovered 'significantly lower achievement in both reading and maths' amongst primary-aged children, most likely attributable to missed learning. For secondary pupils, forgoing 3-4 hours per the main subject each week for a term could potentially impact results by $-6.0 \%$ [28]. Home education has caused significant stress for parents. The Co-Space study from The University of Oxford [29] found that $36.0 \%$ of parents of primary-aged children were substantially worried about their children's behavior, and $45.0 \%$ with secondary-aged children were worried about their children's future. The impact of school closures may be irrecoverable for this generation of young people [30].
The first phase of the research team's research [4] indicated the existence of impacts in each BPS domain and also the relationships between them. New biological issues emerged as people contracted the disease, and pre-existing illnesses were exacerbated (e.g., blood pressure, IBS, diabetes). Biological tissues such as increased blood pressure added to the mental burden of the pandemic and increased anxiety. Mental wellbeing deteriorated with new incidences of anxiety and depression, and existing conditions worsened (e.g., depression). Additionally, existing social issues such as loneliness, limited participation in activities, and poverty, worsened and there were examples where the pressure of home education and home working led to increased stress and higher blood pressure.

In this second phase of research, the team has sought to measure the self-reported perception of the biopsychosocial impacts of the COVID-19 pandemic over time, lending further weight to arguments tentatively developed through the first qualitative phase of work.

\section{Methods}

This paper considers how COVID-19 control measures have impacted self-perceived wellbeing from a biopsychosocial stance. The working hypothesis was that COVID-19 and the accompanying restrictions had had a cumulative, negative impact on wellbeing (BPS axis). This hypothesis was tested in data from a mixed-methods online survey distributed via social media and over 100 diverse organizations (educational, caring, addiction, and LGBTQ+) to widen participation. The survey was approved by the University of Cumbria Ethics Committee. It was open for completion from November 2020 - February 2021; 164 participants volunteered and provided full consent. The survey contained a range of quantitative and qualitative questions. This paper focuses on quantitative responses to a range of self-rating, Likert-style questions on self-reported perception of wellbeing. Data analyses involved correlations of the independent variable time over five data points retrospectively, with one dependent variable, wellbeing, with three dimensions, biological, psychological, and social wellbeing.

The survey included a quantitative, closed question, using a $5 \times 5$ table and ordinal variable, Likert scale (5-1). The BPS objective measures were created from findings of the researchers' first study, which was a biopsychosocial (BPS) axis regarding the first COVID-19 lockdown [4]. As the COVID-19 pandemic continued, it was thought important to investigate the biopsychosocial impact of the pandemic across the various stages from a self-perception stance. An accessible, easy to complete, an online questionnaire was needed where the participant could reflect upon the impact of the pandemic upon them across the different stages.

Participants rated the extent to which COVID-19 and its control measures had impacted their physical health, mental health, social health, and wellbeing during the pandemic's five phases. The definition of 'social' was 'relationships, responsibilities, and support for these, as well as access to activities such as sport and culture'. Impact options were: Very positive effect - improved a lot; Some positive effect improved a little; No change; Some negative affect - worsened a little; Very Negative affect - worsened a lot. 
Table 1: Example of how each questionnaire was scored.

\begin{tabular}{|l|l|l|l|l|l|l|}
\hline & $\begin{array}{l}\text { During the early } \\
\text { stages of the } \\
\text { pandemic }\end{array}$ & $\begin{array}{l}\text { During the } \\
\text { first lockdown }\end{array}$ & $\begin{array}{l}\text { During the } \\
\text { easing } \\
\text { restrictions } \\
\text { of }\end{array}$ & $\begin{array}{l}\text { During the } \\
\text { second } \\
\text { wave/local } \\
\text { restrictions }\end{array}$ & $\begin{array}{l}\text { During the second } \\
\text { lockdown }\end{array}$ & Scoring ** \\
\hline $\begin{array}{l}\text { Physical } \\
\text { Health } \\
\text { (Biological } \\
\text { Domain): }\end{array}$ & $\begin{array}{l}\text { Very positive affect } \\
\text {-improved a lot }\end{array}$ & No change & $\begin{array}{l}\text { Some positive } \\
\text { affect - improved } \\
\text { a little }\end{array}$ & $\begin{array}{l}\text { Some negative } \\
\text { affect - worsened } \\
\text { a little }\end{array}$ & $\begin{array}{l}\text { Some negative affect } \\
- \text { worsened a little }\end{array}$ & $5,3,4,2,2$ \\
\hline $\begin{array}{l}\text { Psychological } \\
\text { Domain }\end{array}$ & $\begin{array}{l}\text { Very negative affect } \\
- \text { worsened a lot. }\end{array}$ & $\begin{array}{l}\text { Some positive } \\
\text { affect } \\
\text { improved a } \\
\text { little }\end{array}$ & $\begin{array}{l}\text { Some negative } \\
\text { affect - worsened } \\
\text { a little }\end{array}$ & $\begin{array}{l}\text { Some Negative } \\
\text { affect - worsened } \\
\text { a little }\end{array}$ & $\begin{array}{l}\text { Some positive affect } \\
- \text { improved a little }\end{array}$ & $1,4,2,2,4$ \\
\hline $\begin{array}{l}\text { Socially } \\
\text { Domain }\end{array}$ & $\begin{array}{l}\text { Some positive affect } \\
\text {-improved a little }\end{array}$ & $\begin{array}{l}\text { Some positive } \\
\text { affect } \\
\text { improved a } \\
\text { little }\end{array}$ & No change & No change & $\begin{array}{l}\text { Some positive affect } \\
- \text { improved a little }\end{array}$ & $4,4,3,3,4$ \\
\hline
\end{tabular}

$* *$ Scoring $=$ Very positive affect - improved a lot $=5$; Some positive affect - improved a little $=4$; No change $=3$; Some Negative affect - worsened a little $=2$; Very Negative affect - worsened a lot $=1$

The five phases of the pandemic were: early stages of the pandemic; first lockdown; easing of restrictions; second wave/local restrictions; second lockdown. These are the fivetime points that have been measured. Therefore, within a $5 \times 5$ table, each participant provided a rating for each data point for each BPS domain separately, thus providing five ratings (1 rating for each of the 5 data points) for physical health, five ratings for mental health, and five ratings for social health; 25 ratings in total. For the scoring of each $5 \times 5$ table, please see table 1 as an example. The researchers created these questions to measure self-reported perceptions of the biopsychosocial impact on participants. The survey offered an opportunity to pilot these.
The questions did not have validity and test-retest reliability. The objective measure had good reliability and internal consistency according to Cronbach Alpha (see section 3.3). Three further questions were then asked which examined participants' perceptions of the relationship between the impacts of the pandemic and their physical, psychological, and social health; this was scored between 1-9 Likert scale from '1 impacting positively to a massive extent, 2, 3, 4, 5 - 'no impact', 6, 7, 8, 9- impacting negatively to a massive extent' (Appendix 2). While the researchers plan on writing an additional publication that will explore the qualitative data from this mixed-methods study, this publication specifically focuses on the quantitative data collected.

Table 2: Demographics of survey respondents.

\begin{tabular}{|c|c|c|c|}
\hline Demographic & Options & Number & Percentage \\
\hline \multirow[t]{3}{*}{ Gender } & Female & 127 & 77.4 \\
\hline & Male & 35 & 21.3 \\
\hline & Did not say & 2 & 1.2 \\
\hline \multirow[t]{10}{*}{ Age in Years } & $11-20$ & 2 & 1.2 \\
\hline & $21-30$ & 38 & 23.2 \\
\hline & $31-40$ & 34 & 20.7 \\
\hline & $41-50$ & 14 & 8.5 \\
\hline & $51-60$ & 36 & 22.0 \\
\hline & $61-70$ & 30 & 18.3 \\
\hline & $71-80$ & 9 & 5.5 \\
\hline & $81-90$ & 0 & 0 \\
\hline & $91-100$ & 0 & 0 \\
\hline & Did not say & 0 & 0 \\
\hline \multirow[t]{8}{*}{ Ethnicity } & $\begin{array}{l}\text { White - English, Welsh, Scottish, Northern Irish } \\
\text { or British }\end{array}$ & 150 & 91.5 \\
\hline & Any other White background & 5 & 3.0 \\
\hline & Asian or Asian British - Bangladeshi & 3 & 1.8 \\
\hline & White - Irish & 2 & 1.2 \\
\hline & Asian or Asian British - Indian & 1 & 0.6 \\
\hline & Mixed or Multiple ethnicity - White and Asian & 1 & 0.6 \\
\hline & Any other ethnic group & 1 & 0.6 \\
\hline & Did not say & 1 & 0.6 \\
\hline \multirow[t]{7}{*}{ Co-habitation } & Partner/Husband/Wife & 75 & 45.7 \\
\hline & Partner and one or more children & 31 & 18.9 \\
\hline & No one & 18 & 11 \\
\hline & One or more children & 14 & 8.5 \\
\hline & Flatmates & 6 & 3.7 \\
\hline & Partner and one or more children and parents & 5 & 3.0 \\
\hline & Parents & 9 & 5.4 \\
\hline
\end{tabular}




\begin{tabular}{|c|c|c|c|}
\hline & Other & 4 & 2.4 \\
\hline \multirow[t]{6}{*}{ Housing Situation } & Own a flat or house & 111 & 67.7 \\
\hline & Renting a flat or house & 28 & 17.1 \\
\hline & Living with parents & 14 & 8.5 \\
\hline & Renting a room & 6 & 3.7 \\
\hline & Part own a flat or house & 3 & 1.8 \\
\hline & Other & 2 & 1.2 \\
\hline \multirow{12}{*}{$\begin{array}{l}\text { Regions( } 9 \text { of } 9 \text { English regions) } \\
\text { ( } 24 \text { of } 38 \text { English counties) }\end{array}$} & Northwest & 74 & 45.1 \\
\hline & Northeast & 18 & 11.0 \\
\hline & East & 13 & 7.9 \\
\hline & Southeast & 7 & 4.3 \\
\hline & East Midlands & 5 & 3.0 \\
\hline & West Midlands & 4 & 2.4 \\
\hline & Scotland & 4 & 2.4 \\
\hline & Yorkshire and Humber & 3 & 1.8 \\
\hline & London & 2 & 1.2 \\
\hline & Southwest & 1 & 0.6 \\
\hline & Ireland & 1 & 0.6 \\
\hline & No answer & 32 & 19.5 \\
\hline
\end{tabular}

\section{Results}

Social and demographic characteristics

In an earlier survey, respondents were highly biased in terms of age, gender, and housing situation [4]. The current survey, conducted for a longer duration of time, was distributed purposively to a wide range of social media networks and varied organizations in order to limit any demographic bias.

There were 164 respondents whose demographics are shown in table 2 above. This survey results indicate a particular segment of UK society at a particular point in time. The experiences of people living in more marginal positions in society who were unable to respond 'online' must be elicited in more appropriate ways.

Self-perception indicators of biopsychosocial wellbeing before COVID-19

The survey data provided a self-rating of biological, psychological, and social wellbeing before the pandemic started. This established a baseline and demographic understanding for each participant. The questions used to elicit this data were: "Thinking back to January 2020, how would you have rated your physical health (mental health / social aspects of life) at that time?". The response option was a five-point Likert scale; very good, good, moderate, bad, very bad. The frequencies, including the percentages, standard deviation, mean, and range, have been calculated for each BPS domain as reported below. Biological factors of physical health status before COVID-19 were reported by 156 participants. Eight incomplete responses were omitted from the data (Figure 1).

Descriptive statistical tools showed a mean of 1.89 , a range of 3 (1-4), and a standard deviation of 0.792 , indicating the vast majority of survey participants perceived themselves as in good or very good biological health before the pandemic. Psychological factors of mental health status before COVID-19 were reported by 158 participants. Six partial responses were omitted from the data (Figure 2).

Descriptive statistical tools showed a mean of 2.01, a range of 3 (1-4), and a standard deviation of .948indicatingthat most survey participants also perceived themselves as in good or very good psychological health before the pandemic. The social aspects of life before COVID-19 were reported by 161 participants. Three incomplete responses were omitted from the data (Figure 3).

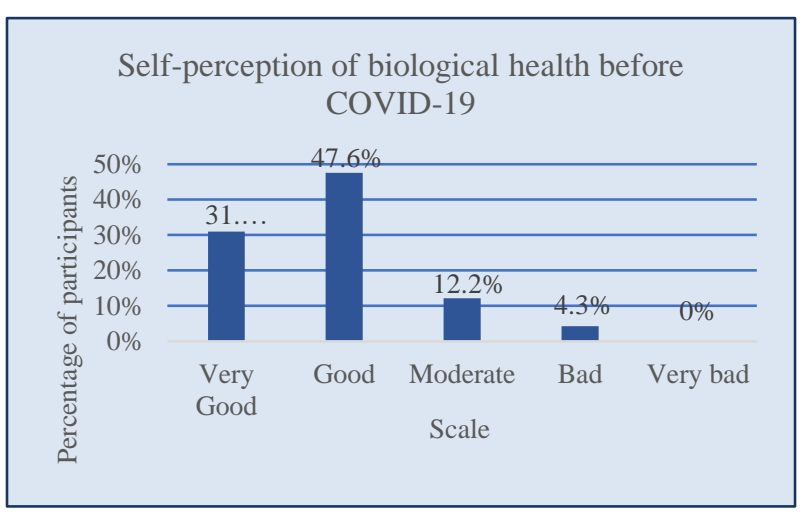

Figure 1 Self-perception of biological health

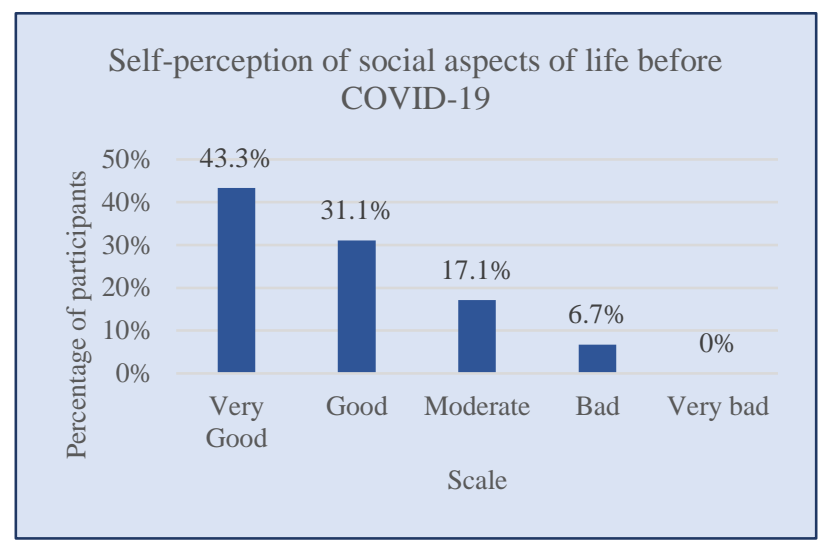

Figure 2 Self-perception of psychological health

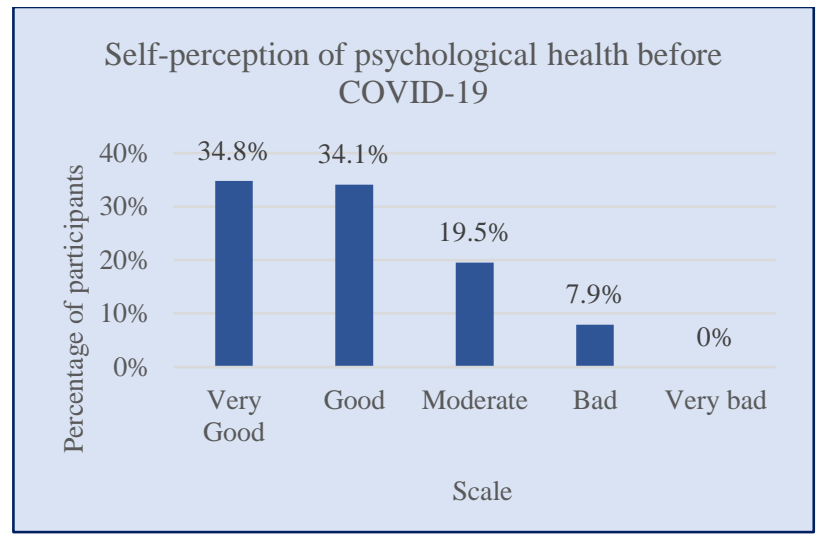

Figure 3 Self-perceptions of social aspects of life 
Changes in self-perception of the biopsychosocial wellbeing throughout the pandemic control measures

Participants responded to a quantitative, closed question in order to ascertain the changes to their self-perception of their biopsychosocial wellbeing over time. The question was formatted with ordinate variables at five points in time, each measured with a five-point Likert scale. The participants were asked, "Please rate the extent to which COVID-19 and its control measures has affected your physical health during the five phases of the pandemic". The question was repeated for each aspect of the biological, psychological, and social wellbeing (please see Appendix 1).

The five points in time were:

a. During the early stages of the pandemic

b. During the first lockdown

c. During the easing of restrictions

d. During the second wave/local restrictions

e. During the second lockdown

The five possible answer options for each time period were:

a. Very positive affect - improved a lot

b. Some positive affect - improved a little

c. No change

d. Some negative affect - worsened a little

e. Very negative affect - worsened a lot

The percentages of each time period and rating can be seen in Table 3 .

Table 3 Percentage changes in the self-perception of biological, psychological, and social wellbeing over time

\begin{tabular}{|c|c|c|c|}
\hline $\begin{array}{l}\text { Period of time } \\
\text { in pandemic }\end{array}$ & $\begin{array}{l}\text { Biological } \\
\%\end{array}$ & $\begin{array}{l}\text { Psychological } \\
\%\end{array}$ & $\begin{array}{c}\text { Social } \\
\%\end{array}$ \\
\hline \multicolumn{4}{|l|}{ Early Stages } \\
\hline Very negative & 2.5 & 7.5 & 13.2 \\
\hline Negative & 15.1 & 32.1 & 34 \\
\hline No change & 69.2 & 49.1 & 45.3 \\
\hline Positive & 8.8 & 8.8 & 6.3 \\
\hline Very positive & 3.8 & 1.9 & 0.6 \\
\hline \multicolumn{4}{|l|}{ First Lockdown } \\
\hline Very negative & 9.4 & 19.5 & 44.7 \\
\hline Negative & 26.4 & 40.3 & 36.5 \\
\hline No change & 26.4 & 20.1 & 10.1 \\
\hline Positive & 26.4 & 14.5 & 6.9 \\
\hline Very positive & 10.7 & 5.0 & 1.3 \\
\hline \multicolumn{4}{|l|}{$\begin{array}{l}\text { Easing of } \\
\text { Restrictions }\end{array}$} \\
\hline Very negative & 1.9 & 1.9 & 7.5 \\
\hline Negative & 12.6 & 20.8 & 31.4 \\
\hline No change & 49.7 & 35.8 & 23.3 \\
\hline Positive & 28.9 & 33.3 & 31.4 \\
\hline Very positive & 6.3 & 7.5 & 5.7 \\
\hline \multicolumn{4}{|c|}{$\begin{array}{l}\text { Second } \\
\text { Wave/Restrictions }\end{array}$} \\
\hline Very negative & 4.4 & 9.4 & 19.5 \\
\hline Negative & 30.8 & 44.7 & 50.9 \\
\hline No change & 49.7 & 35.2 & 23.3 \\
\hline Positive & 10.1 & 8.8 & 4.4 \\
\hline Very positive & 4.4 & 1.3 & 1.3 \\
\hline \multicolumn{4}{|c|}{ Second Lockdown } \\
\hline Very negative & 12.6 & 17 & 37.7 \\
\hline Negative & 34.6 & 46.5 & 40.9 \\
\hline No change & 38.4 & 28.9 & 15.7 \\
\hline Positive & 11.3 & 5.7 & 3.8 \\
\hline Very positive & 2.5 & 1.3 & 1.3 \\
\hline
\end{tabular}

The scale was modified as a data set from 5-1: $5=$ very positive affect - improved a lot, $4=$ some positive affect - improved a little, $3=$ No change, $2=$ some negative affect - worsened a little, $1=$ very negative affect - worsened a lot. The five periods of time (During the early stages of the pandemic $=1$, During the first lockdown $=2$, During the easing of restrictions $=3$, During the second wave/local restrictions $=4$, During the second lockdown $=5)$. Incomplete surveys $(<100 \%, n=6)$ were omitted from the data set using listwise deletion, leaving 164 surveys for analysis. To test for differences between the five periods of time across the COVID-19 pandemic separately for each section of the BPS axis (Biological, psychological \& social), a nonparametric Friedman Test was implemented. In order to investigate where the most significant differences between the five periods of time across the pandemic were, a Wilcoxon signed-rank test was conducted. Each dimension of the biopsychosocial framework was then analyzed separately to show which time point had the greatest difference in perception of biopsychosocial health.

\section{Questionnaire Reliability}

To determine the internal consistency of the three $5 \times 5$ objective measures (i.e., biological, psychological, and social values - 15 items in total) in terms of reliability, Cronbach's alpha was calculated for the existing correlation between each item of the measures and the remaining items of their total (total score). Cronbach's alpha showed the three measures to reach acceptable reliability $\alpha=0.75$. The Cronbach's alpha values presented in the measures ranged from 0.75-0.77. Determinant values of 0.70 and above are considered acceptable; closer to 0.80 or greater is preferred [31]. Values under 0.7 but close to 0.6 can be regarded as satisfactory [32]. Most items appeared to be worthy of retention, resulting in a decrease in the alpha if deleted. The exception to this was the social $5 \times 5$ scale during the first lockdown and the second lockdown. If either were removed, the alpha score would still be 0.75 . Therefore, rather than removal, it is advised for the measures to be modified for future use and for the Cronbach analysis to be implemented, as well as additional reliability and validity testing, as shown in Table 4 below. The $5 \times 5$ measures can be seen below in Appendix 1, with the 15 statements, across the three domains.

Table 4 Cronbach's alpha, if the items were discarded $(\alpha-x)$

\begin{tabular}{|l|l|}
\hline Questions & $(\boldsymbol{\alpha}$-x) \\
\hline Physical Health Early stages of pandemic & 0.77 \\
\hline Physical Health First lockdown & 0.76 \\
\hline Physical Health First easing of restrictions & 0.76 \\
\hline Physical Health First local restrictions & 0.76 \\
\hline Physical Health Second lockdown & 0.77 \\
\hline Mental Health Early stages of pandemic & 0.76 \\
\hline Mental Health First lockdown & 0.75 \\
\hline Mental Health First easing of restrictions & 0.75 \\
\hline Mental Health First local restrictions & 0.76 \\
\hline Mental Health Second lockdown & 0.76 \\
\hline Social Early stages of pandemic & 0.76 \\
\hline Social First lockdown & 0.75 \\
\hline Social First easing of restrictions & 0.75 \\
\hline Social First local restrictions & 0.75 \\
\hline Social Second lockdown & 0.75 \\
\hline
\end{tabular}

* Cronbach's Alpha 


\section{Biological dimension}

The Friedman test showed a statistically significant difference in the self-perception of the impact of COVID-19 throughout the pandemic from the perspective of the biological aspect of BPS, $\chi 2(4)=63.99, p<0.001$. Kendall's Coefficient of Concordance was 0.1 , showing a small effect. A Wilcoxon Signed-Rank's test indicated no significant difference between the early stages of the pandemic and the first lockdown $(\mathrm{Z}=-.81$, $\mathrm{p}=0.42$ ). However, there was a statistically significant positive impact on biological wellbeing between the first lockdown and the first easing of restrictions $(\mathrm{Z}=-2.35, \mathrm{p}<0.05)$. Alternatively, between the first easing of restrictions and the first local restrictions, there was a significant negative impact $(\mathrm{Z}=-5.52$, $\mathrm{p}$ $<0.001$ ), similarly for biological impact between the second lockdown and the first local restrictions on $(\mathrm{Z}=-3.21, \mathrm{p}<0.001)$ and between the second lockdown and the early stages of the pandemic $(\mathrm{Z}=-4.14, \mathrm{p}<0.001)$. The Wilcoxon test shows that the easing of restrictions after the first lockdown increased scores, indicating a positive impact on biological wellbeing. However, the change from local restrictions to the second lockdown decreased participants' scores significantly, showing a negative impact on biological wellbeing. Comparisons between the second lockdown and the early stages of the pandemic confirm a significant negative impact on physical health.

Table 5 Self-perception Biological Dimension Descriptive Statistics

\begin{tabular}{|l|l|l|l|l|l|l|}
\hline Variables & Z & $\mathrm{p}$ & Mean & \multicolumn{2}{l|l}{$\begin{array}{l}\text { Rank bi-serial } \\
\text { correlations }\end{array}$} & Impact Direction \\
\hline & & & & Effect Size & P value & \\
\hline First lockdown vs (Early stages of pandemic) & -0.81 & 0.42 & 2.96 & 0.383 & 0.000 & - \\
\hline First easing of restrictions vs (First lockdown) & -2.35 & 0.02 & 3.03 & 0.271 & 0.001 & Positive \\
\hline First local restrictions vs (First easing of restrictions) & -5.52 & 0.000 & 3.25 & 0.391 & 0.000 & Negative \\
\hline Second lockdown vs (First local restrictions) & -3.21 & 0.001 & 2.79 & 0.521 & 0.000 & Negative \\
\hline Second lockdown vs (Early stages of pandemic) & -4.14 & 0.000 & 2.56 & 0.061 & 0.444 & Negative \\
\hline
\end{tabular}

** $(0.001)$ and $(0.000)=\mathrm{p}<0.001$ Significant Correlations; A correlation of -1.0 shows a perfect negative correlation measurement, whereas a correlation of 1.0 shows a perfect positive correlation.

\section{Psychological dimension}

The Friedman test showed a statistically significant difference in perception of impact across the COVID-19 pandemic on psychological wellbeing $\chi 2(4)=118.939, \mathrm{p}<0.001)$. Kendall's Coefficient of Concordance was 0.1, showing a small effect.

A Wilcoxon signed-rank test demonstrated a significant, negative, psychological impact between the early stages of the pandemic and the first lockdown $(\mathrm{Z}=-2.47, \mathrm{p}<0.05)$. The easing of restrictions following the first lockdown had a statistically significant, positive impact on psychological wellbeing $(\mathrm{Z}=-$
6.61, $\mathrm{p}<\mathrm{p}<0.001)$. However, the first local restrictions following the first easing demonstrated another significant, negative psychological impact $(\mathrm{Z}=-7.56, \mathrm{p}<0.001)$, this was also apparent during the move from the first local restrictions to the second lockdown $(\mathrm{Z}=-3.48, \mathrm{p}<0.001)$. Further, the Wilcoxon Test between scores for the early stages of the pandemic with those for the second lockdown demonstrated a negative, statistically significant impact on psychological wellbeing.

Table 6 Self-perception Psychological Dimension Descriptive Statistics

\begin{tabular}{|l|l|l|l|l|l|l|}
\hline Variables & $\mathrm{Z}$ & $\mathrm{p}$ & Mean & \multicolumn{2}{l|}{$\begin{array}{l}\text { Rank bi-serial } \\
\text { correlations }\end{array}$} & Impact \\
\hline & & & & \multicolumn{1}{|c|}{ Effect Size } & P value & \\
\hline First lockdown vs (Early stages of pandemic) & -2.472 & 0.013 & 2.65 & 0.436 & 0.000 & Negative \\
\hline First easing of restrictions vs (First lockdown ) & -6.613 & 0.000 & 2.45 & 0.226 & 0.004 & Positive \\
\hline First local restrictions vs (First easing of restrictions) & -7.561 & 0.000 & 3.24 & 0.351 & 0.000 & Negative \\
\hline Second lockdown vs (First local restrictions) & -3.480 & 0.001 & 2.47 & 0.646 & 0.000 & Negative \\
\hline Second lockdown vs (Early stages of pandemic) & -4.030 & 0.000 & 2.27 & 0.117 & 0.142 & Negative \\
\hline
\end{tabular}

** $(0.001)$ and $(0.000)=\mathrm{p}<0.001$ Significant Correlations; A correlation of -1.0 shows a perfect negative correlation measurement, whereas a correlation of 1.0 shows a perfect positive correlation.

\section{Social dimensions}

The Friedman test showed a statistically significant difference in the self-perception of the impact socially across the COVID19 pandemic $\chi 2(4)=186.43, \mathrm{p}<.001$. Kendall's Coefficient of Concordance was 0.2 , showing a small effect. A Wilcoxon signed-rank test indicated significant differences from the first lockdown across the periods of the COVID-19 pandemic to the second lockdown. Between the first lockdown and the early stages of the pandemic, there was a significantly negative impact on social aspects $(\mathrm{Z}=-7.20, \mathrm{p}<.001)$. However, there was a significantly positive impact on social aspects between the first lockdown and the first easing of restrictions $(Z=-8.61$, $\mathrm{p}$ <.001). On the other hand, there was a significantly negative impact on social aspects between the first local restrictions and the first easing of restrictions $(\mathrm{Z}=-7.519, \mathrm{p}<.001)$. Moreover, between the second lockdown and the first local restrictions, there was a significantly negative impact on social aspects $(\mathrm{Z}=$ $4.690, \mathrm{p}<.001)$. Additionally, comparing the scores from the second lockdown to the early stages of the pandemic also revealed a significant negative impact on participants from a social perspective $(\mathrm{Z}=-5.981, \mathrm{p}<0.001)$. The Wilcoxon test shows a negative impact for the majority of participants from the start of the first lockdown and the first stages of the pandemic. Furthermore, from the easing of the first lockdown, the negative social impact decreased, having a positive impact. Conversely, from local restrictions to the second lockdown, the negative impact on the social domain of participants started to decline. 
Table 7 Self-perception Social Domain Descriptive Statistics

\begin{tabular}{|l|l|l|l|l|l|l|}
\hline Variables & $\mathrm{Z}$ & $\mathrm{p}$ & Mean & \multicolumn{2}{l|}{$\begin{array}{l}\text { Rank bi-serial } \\
\text { correlations }\end{array}$} & Impact Direction \\
\hline & & & & \multicolumn{1}{l}{ Effect Size } & P value & \\
\hline First lockdown vs (Early stages of pandemic) & -7.204 & 0.000 & 2.47 & 0.527 & 0.000 & Negative \\
\hline First easing of restrictions vs (First lockdown) & -8.612 & 0.000 & 1.83 & 0.344 & 0.000 & Positive \\
\hline First local restrictions vs (First easing of restrictions) & -7.519 & 0.000 & 2.96 & 0.415 & 0.000 & Negative \\
\hline Second lockdown vs (First local restrictions) & -4.690 & 0.000 & 2.16 & 0.672 & 0.000 & Negative \\
\hline Second lockdown vs (Early stages of pandemic) & -5.981 & 0.000 & 1.89 & 0.276 & 0.000 & Negative \\
\hline
\end{tabular}

** $(0.001)$ and $(0.000)=\mathrm{p}<0.001$ Significant Correlations; A correlation of -1.0 shows a perfect negative correlation measurement, whereas a correlation of 1.0 shows a perfect positive correlation.

Self-perception of the impact across biopsychosocial domains

Using the mean score from each of the 15 statements across the five stages of the COVID-19 pandemic enables the self- perception of the impact of the pandemic across the three dimensions to be shown. These are considerable, more so between psychological and social domains during the later stages of the pandemic. See chart four below.

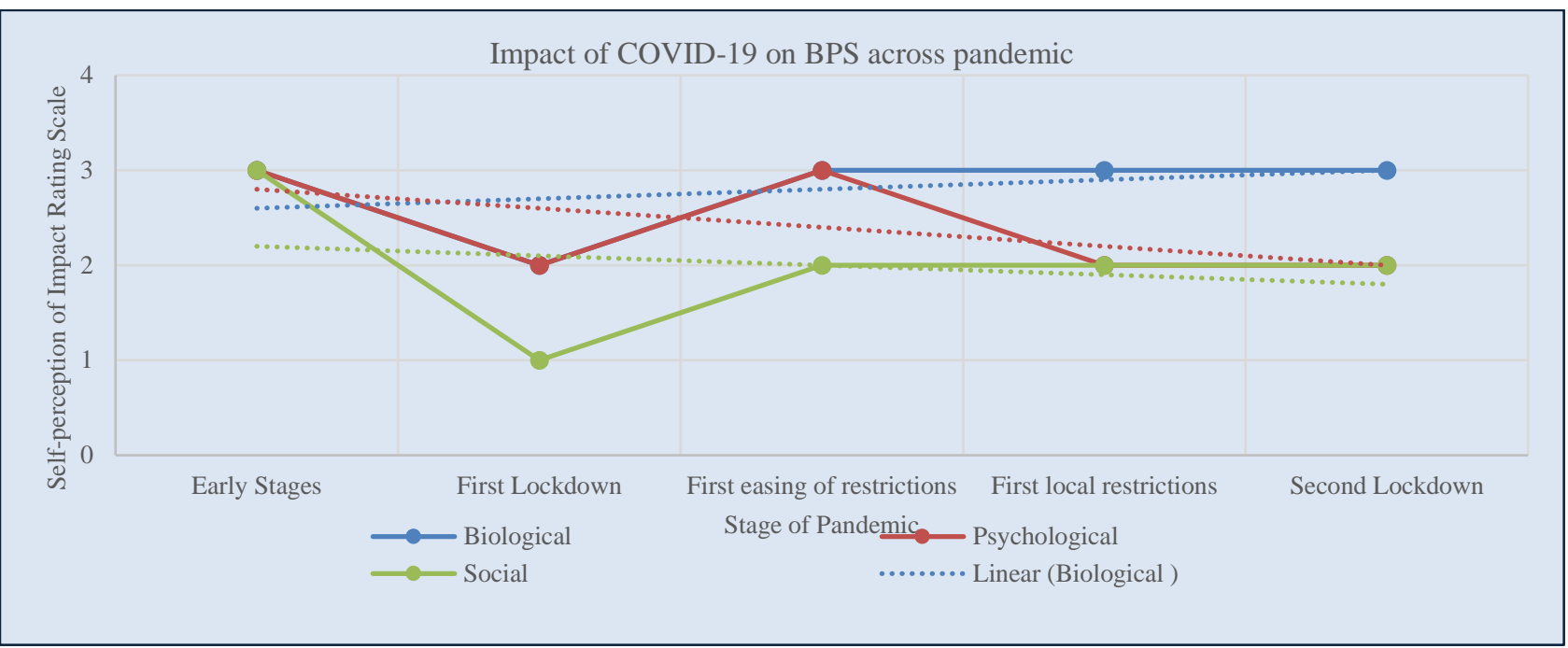

Figure 4 Self-perception Impact of COVID-19 on BPS across pandemic; Scale - $(5=$ Very positive, $4=$ Positive, $3=$ No change, $2=$ Negative, $1=$ Very Negative)

During the later stages of the COVID-19 pandemic, a positive correlation was observed for biological health between the first local restrictions and the second lockdown $r=0.52, p<0.001$. See table 8 below.

Table 8 Correlations of the impact of pandemic across BPS

\begin{tabular}{|c|c|c|c|c|c|}
\hline Biological & Bio. ES & Bio. L1 & Bio. E1 & Bio. R1 & Bio. L2 \\
\hline Bio. ES & 1 & & & & \\
\hline Bio. L1 & $0.383(0.000)$ & 1 & & & \\
\hline Bio. E1 & 0.028 & $0.271(0.001)$ & 1 & & \\
\hline Bio. R1 & -0.151 & 0.70 & $0.391(0.000)$ & 1 & \\
\hline Bio. L2 & 0.061 & 0.63 & -0.029 & $0.521(0.000)$ & 1 \\
\hline Psychological & Psy. ES & Psy. L1 & Psy. E1 & Psy.R1 & Psy. L2 \\
\hline Psy. ES & 1 & & & & \\
\hline Psy. L1 & $0.436(0.000)$ & 1 & & & \\
\hline Psy. E1 & 0.093 & 0.226 & 1 & & \\
\hline Psy. R1 & 0.103 & 0.105 & $0.351(0.000)$ & 1 & \\
\hline Psy. L2 & 0.117 & 0.105 & 0.149 & $0.646(0.000)$ & 1 \\
\hline Social & Soc. ES & Soc. L1 & Soc. E1 & Soc.R1 & Soc. L2 \\
\hline Soc. ES & 1 & & & & \\
\hline Soc. L1 & $0.527(0.000)$ & 1 & & & \\
\hline Soc. E1 & $0.262(0.001)$ & $0.344(0.000)$ & 1 & & \\
\hline Soc. R1 & $256(0.001)$ & $0.329(0.000)$ & $0.415(0.000)$ & 1 & \\
\hline Soc. L2 & $0.276(0.000)$ & $0.514(0.000)$ & $0.286(0.000)$ & $0.672(0.000)$ & 1 \\
\hline
\end{tabular}

** $(0.001)$ and $(0.000)=\mathrm{p}<.001$ Significant Correlations; A correlation of -1.0 shows a perfect negative correlation measurement, whereas a correlation of 1.0 shows a perfect positive correlation. Key: ES - Early stages of the pandemic; L1 - First lockdown; E1 - First easing of restrictions; R1 - First local restrictions; L2 - Second lockdown 
Self-Perception of the relationships between the biopsychosocial dimensions

The survey respondents were asked to rate the strength of the impact of one dimension of the biopsychosocial framework on another on a 1-9 Likert scale from ' 1 - impacting positively to a massive extent, 2, 3, 4, 5 - 'no impact', 6, 7, 8, 9- impacting negatively to a massive extent. This provided an insight into whether and to what extent respondents saw a relationship between the three dimensions. The relationships are explored below (Figure 5).

Of the 164 participants, just under a third believed their biological health positively impacted their psychological health $(31.1 \%)$, and around a fifth reported no impact. However, half of the participants $(50.6 \%)$, to varying degrees, perceived their physical health to impact their mental health negatively (Figure 6).

This shows that while a small proportion of participants (15.2\% of 163 respondents) perceived their mental health to have impacted positively on their physical health and just under a third felt it had not impacted, over half of participants (55.5\%) reported that their mental health had impacted negatively on their physical health (Figure 7).

The greatest proportion of participants did not perceive an impact between social aspects of life and their physical health (47.0\%); however, around one-third (38.4\% of 163 respondents) perceived this to have impacted negatively (Figure 8 ).

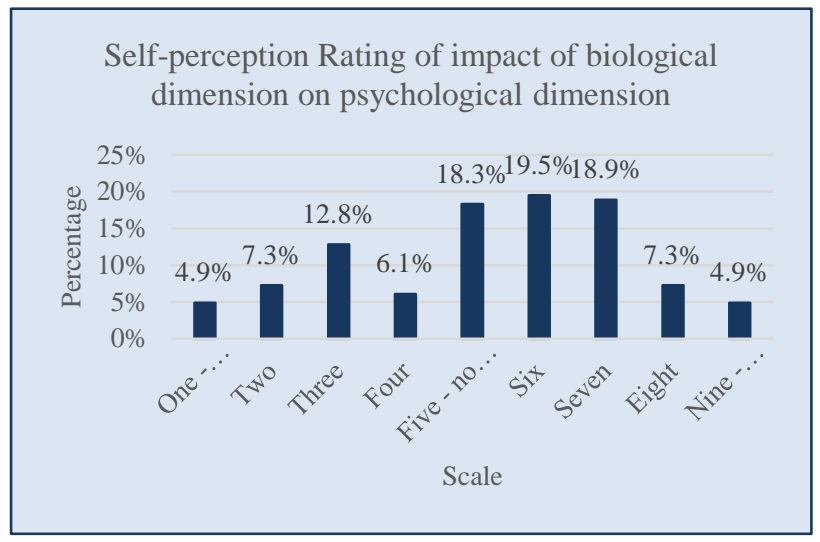

Figure 5 Self-perception impact of physical health on mental health; Descriptive Statistics $-\mathrm{M}=5.26, \mathrm{SD}=2.089$, Range $=8(1-9)$.

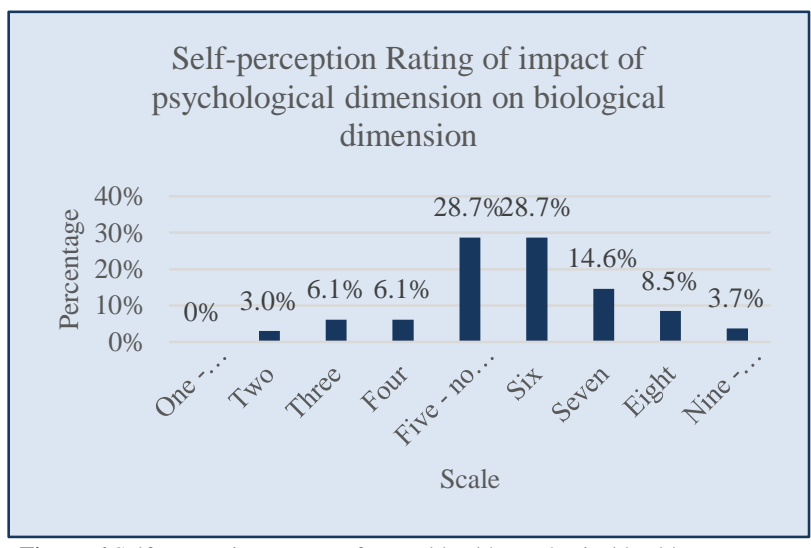

Figure 6 Self-perception Impact of mental health on physical health; Descriptive Statistics $-\mathrm{M}=6.00, \mathrm{SD}=1.526$, Range $=7$ (2-9).

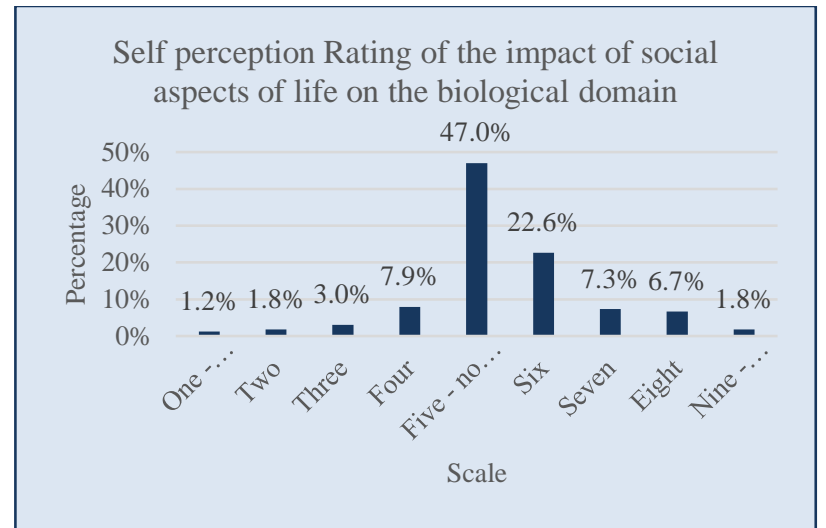

Figure 7 Self-perception Impact of social aspects of life on physical health; Descriptive Statistics $-\mathrm{M}=6.00, \mathrm{SD}=1.526$, Range $=7(2-9)$.

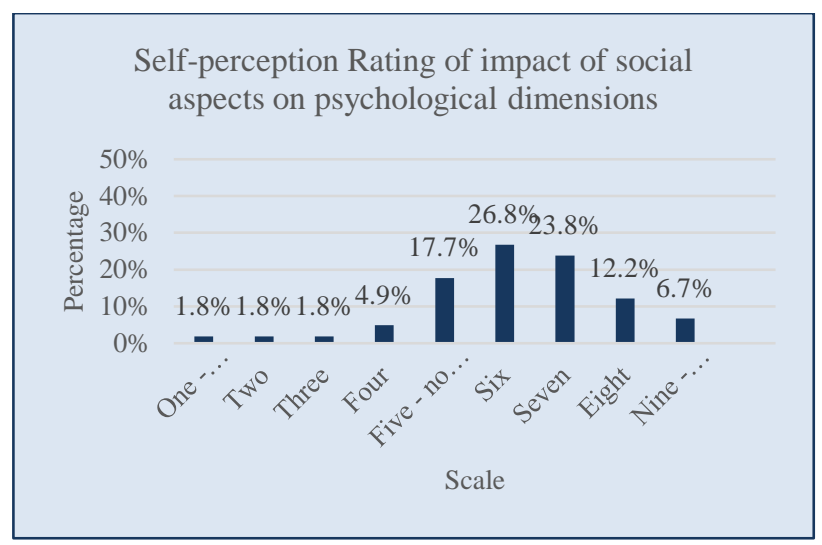

Figure 8 Self-perception Impact of social aspects of life on mental health; Descriptive Statistics $-\mathrm{M}=6.21, \mathrm{SD}=1.641$, Range $=8(1-9)$.

\section{Discussion}

The quantitative data collected in this research has shown that biological, psychological, and social health from a selfperception stance has each been impacted negatively by COVID-19 and associated control measures. This adds quantification and statistical significance to the findings from earlier qualitative research [4].

Our previous research theorized a linkage between the three areas of the biopsychosocial framework. We can here quantify that people perceive that the biological, psychological, and social factors are interrelated and mutually influencing. The majority of the data points across the pandemic had a negative impact and got worse over time, except between the first stage of lockdown and the easing of restrictions, when there was a positive impact across all three domains. During the later stages of the pandemic, there was a positive correlation for the selfperception that biological health had improved. Nevertheless, the correlation was not significantly strong. However, as well as the positive impacts, the negative impact perceptions were statistically significant. Given the self-perception of the negative impact of the pandemic and its control measures on all factors, this research begins to make visible the potential for self-reinforcing negative cycles of impact. Therefore, the importance of tackling psychological as well as social issues arising from the pandemic, is highlighted. Currently, many of these issues are well documented as a single issue that suggests a mono-professional response to the issues. A biopsychosocial 
approach would facilitate a holistic and integrated approach to managing the consequences of COVID-19, just as it has facilitated change in other disciplines. Examples of successful applications of the BPS framework were identified in the introduction; further, the management of pain has been particularly transformed with the introduction of a BPS approach as Bevers, Watts, Kishino, Gatchel, et al. [33] state, its introduction has led to the implementation of "interdisciplinary, multifaceted pain management strategies". This research suggests that such an approach would benefit responses to COVID-19. The impact on each and interrelatedness of the biopsychosocial impacts indicates support is needed across all three domains of the biopsychosocial framework and psychological and social support. This involves an integrated response from all sectors (health, social, educational, employment, leisure) and all types of organizations (statutory, voluntary, private, charitable). If the pandemic continues, extra funding will likely be needed for services to utilize a multidisciplinary and interdisciplinary approach as previously advocated [4]. Such a wider literature on the biological, psychological, and social impacts cited in the introduction, coupled with this research indicating the relationship between these three factors, emphasizes the importance of more than just a health response. Just how would this work in practice?

Examples of implementing the BPS framework show a single lead professional initially employing the approach, although a multidisciplinary team may become involved later. Ideally, each person experiencing negative outcomes from COVID-19 would have a single professional to support them. Given the range of issues highlighted in this research, it is likely that health, mental health, social care, education, and employment practitioners will be seeing more patients. This makes it more challenging to embed and coordinate a BPS approach. An attitudinal change and skills development may be needed for practitioners to understand and address issues outside their traditional professional boundaries actively. These would also need support with appropriate tools, protocols, and success measures [34]. Directors, leaders, and managers are responsible for educating and supporting their staff to perform within a BPS framework. This may appear intimidating and complicated, but other researchers have verified the possibility through asking simple questions: "And how are you.... and how can we help?" [35]. The energy used will not only ameliorate the situation for those suffering from the impacts of COVID-19, but it will also bring rewards for staff. Ultimately this will prepare the way for the vision of integrated working highlighted in the NHS Long Term Plan [36] and generate a 'model of integration' rather than an integrated model. Our research has also made evident the impact of the duration of the pandemic and its control measures. At the point of data collection, the UK was in a second lockdown. The biopsychosocial impact of this year-long change to life cannot be underestimated, and significant resources will need to be coordinated to leverage any 'return to normal. The main study limitation is its sample size. A larger and wider sample is needed to increase the representativeness of the data and the generalization of the results across the UK population. The control measures themselves were digitally limiting, and while a wide range of demographics is shown, they are not representative of the breadth or constitution of society. Therefore, there is a limitation in this survey of female, 21-30-year-old, White British, home-owning, married respondents from the North West of England. Regrettably, this is in keeping with other research findings that females are more likely than males to participate in surveys $[37,38,39]$, and those with white skin are more likely to participate than their non-white counterparts [37, 40,41]. Although 164 participants took part in the study, the majority of these $-69(42 \%)$ were from Cumbria and $15(9 \%)$ from Tyne and Wear. Most other counties were represented by only one or two participants. A small number of participants, 26 (16\%), declined to reveal the county in which they lived. Consequently, these results are not representative of the experiences of individuals across the UK. Although the survey was intended for the UK only, there was one response $(0.6 \%)$ from Europe (Switzerland) and one response $(0.6 \%)$ each from the USA and Canada. This data was removed from the survey to reduce bias. Further exploration of the post-pandemic biopsychosocial recovery of current participants through a follow-up study would be valuable. The $5 \times 5$ tables for each BPS domain have created an objective quantitative measure utilizable in future research into pandemics and their control measures to assess the impact of the pandemic across time.

However, generalization is problematic as the $5 \times 5$ BPS quantitative questionnaire measured the self-perception of the impact of the pandemic on wellbeing was self-developed by the study researchers, with no prior validity or reliability testing. Therefore, further investigation is required for the selfdeveloped measure to be implemented in future research to test for validity and reliability. The MOS 36-item short-form health survey (SF-36) [42] could have been implemented with specific subscales such as depression, anxiety, mental wellbeing, physical function and social withdraw, etc. However, measuring only negative impacts also brings limitations. The -in-house questionnaire created for this research study was devised to allow the participant to express the positive or negative impact of the pandemic and limiting this to 15 statements in total reduced the length of time required to complete. In hindsight, using a validated questionnaire such as PROMIS (PatientReported Outcomes Measurement Information System) [43] may have given scientific rigor due to its established validity and reliability. However, it is not COVID-19 pandemic specific, and the copious questions may have led to participant attrition. Meanwhile, an alternative measure was developed by AlSabbah, et al.[44] examining the BPS impacts on wellbeing has already been tested for reliability and has good validity. However, this has only been used within the UAE culture [44], so it would require further exploration before UK implementation. As participants have been asked to recall biological, psychological, and social responses to the pandemic over a year, recall bias may also be present [45]. Positivistic, this is problematic. Exaggeration, underestimation, or forgetting may distort pandemic impacts, and this should be borne in mind when studying the results. However, post-optimistically and from a BPS perspective, the meaning each participant makes of their experiences is of significance. If a minor impact is remembered as significant, it will have significance for an individual no matter how well it correlates to an objective measure. Consequently, this research represents the BPS impacts perceived by participants, and a more detailed narration 
will be explored in the future qualitatively focused paper. Further limitations discussed include the bias in age, gender, ethnicity, and socioeconomic status inherent in the sample for both studies. Once restrictions are eased, further research is recommended in marginalized communities where people live in the most challenging circumstances. Thus, a full understanding of the lived experience of COVID-19 and the extent to which a BPS framework would assist recovery can be attained.

\section{Conclusion}

Previous qualitative research [4] provided an insight into the varied lived experiences of the pandemic. This second quantitative study has provided objectivity and statistical insight of the specific impact of each data point across the pandemic from the self-reported perception of each participant rather than at a single point in time. Although not generalizable to a global or even UK population, the responses provided in our UK survey sample show that the COVID-19 pandemic and its control measures have impacted more negatively on biological health, psychological health, and social life throughout the last year. These three elements interact, mutually reinforcing one another at different data points. If a validated questionnaire was implemented with larger sample size, stronger correlations might have evolved, and more accurate conclusions could have been made regarding the interconnectedness of the biopsychosocial axis while measuring the true positive and negative impacts of the pandemic on wellbeing. Therefore, a swift return to 'normal' life is critical to prevent the accrual of further negative outcomes. Urgent resources are needed to address biological, psychological, and social issues promptly and effectively, for which an integrated biopsychosocial approach could be influential. We advocate a support network for those dealing with the pandemic consequences, to which service professionals can direct their staff in addition to an integrated leverage system of working in order to achieve better outcomes for all.

\section{Abbreviation}

AIDS: Acquired Immune Deficiency Syndrome; BPS: Biopsychosocial; COVID-19: Coronavirus Disease-19; E1: First Easing of Restrictions; IFS; ES: Early Stages of Pandemic; Institute for Fiscal Studies: L1: First Lockdown; L2: Second Lockdown; M: Mean; MOS: Medical Outcomes Study; NHS: National Health Service; p: p-value; PROMIS; Patient-Reported Outcomes Measurement Information System: R1: First Local Restrictions; SD: Standard Deviation; SF-36: Short Form Health Survey 36 Items; SPSS: Statistical Package for Social Science; UK: United Kingdom; USA: United States of America; Z: Z Value of Wilcoxon Signed Rank Test

\section{Declaration}

\section{Acknowledgment}

We would like to thank all the participants for their responses and insight during the COVID-19 pandemic.

\section{Funding}

The authors received no financial support for their research, authorship, and/or publication of this article.
Availability of data and materials

Data will be available by emailing Professor Kaz Stuart kaz.stuart@cumbria.ac.uk.

Authors' contributions

Samuel Grimwood (SG), Kaz Stuart (KS), Ruth Browning (RB), Elaine Bidmead (EB) and Thea Winn-Reed (TWR) were the designers of the study, coordinating all aspects of the research and drafting and reviewing the article. Samuel Grimwood (SG), Kaz Stuart (KS), Ruth Browning (RB), Elaine Bidmead (EB) and Thea Winn-Reed (TWR) contributed to operationalizing data collection. Samuel Grimwood (SG) conducted the Wilcoxon Signed Rank Test and follow-up tests, as well as the interpretation of the study. Ruth Browning (RB) finalized the demographics and conducted the analysis of the interrelationships between the BPS axis and the interpretation. All authors (SG, KS, RB, EB \& TWR) have read, contributed to amending and collectively approved the final version of the manuscript.

Ethics approval and consent to participate

We conducted the research following the Declaration of Helsinki. The ethical considerations considered institutional guidance and relevant social media research guidance (Social Media Research Group, 2016). Ethical permission was granted by the University of Cumbria Ethics Committee with approval number 19/41 on 30th March 2020 Cumbria, United Kingdom. Participant consent was secured via the JISC Online Survey participant information and consent section. All narratives were anonymized for analysis with email addresses securely stored on an encrypted device to ensure withdrawal was possible and any safeguarding concerns followed up or referred to relevant professionals.

Consent for publication

Not applicable

Competing interest

The authors declare that they have no competing interests.

Open Access

This article is distributed under the terms of the Creative Commons Attribution 4.0 International License (http://creativecommons.org/licenses/by/4.0/), which permits unrestricted use, distribution, and reproduction in any medium, provided you give appropriate credit to the original author(s) and the source, provide a link to the Creative Commons license, and indicate if changes were made. The Creative Commons Public Domain Dedication waiver (http://creativecommons.org/publicdomain/zero/1.0/) applies to the data made available in this article, unless otherwise stated.

Author details

${ }^{1}$ University of Derby, Human Science Research Centre, Derby, United Kingdom

${ }^{2}$ University of Cumbria, Centre for Research in Health and Society, Carlisle, United Kingdom

Article Info

Received: 28 May 2021

Accepted: 03 July 2021

Published: 20 July 2021 


\section{References}

1. Bambra C, Riordan R, Ford J, Matthews F. The COVID19 pandemic and health inequalities. $\mathrm{J}$ Epidemiol Community Health. 2020 Nov;74(11):964-968. DOI: 10.1136/jech-2020-214401. Epub 2020 Jun 13. PMID: 32535550; PMCID: PMC7298201.

2. Mackley A, McInnes R. (2021) Coronavirus: Universal Credit during the Crisis. London: House of Commons Library.https://researchbriefings.files.parliament.uk/docum ents/CBP-8999/CBP-8999.pdf

3. Trust T. (2021) New report reveals how coronavirus has affected food bank use. Accessed 25/2/21 at: https://www.trusselltrust.org/2020/09/14/new-reportreveals-how-coronavirus-has-affected-food-bank-use/

4. Stuart K, Faghy MA, Bidmead E, Browning R, Roberts C, Grimwood S, Winn-Reed T. A biopsychosocial framework for recovery from COVID-19, International Journal of Sociology and Social Policy 2020: 40(9/10): 1021-1039. DOI:10.1108/IJSSP-07-2020-0301

5. Engel GL. The need for a new medical model: a challenge for biomedicine. Science 1977; 196(4286), 129-136. DOI: $10.1126 /$ science. 847460

6. Wade DT, Halligan PW. The biopsychosocial model of illness: a model whose time has come. Clin Rehabil. 2017 Aug;31(8):995-1004. doi: 10.1177/0269215517709890.

7. Vögele C. (2015). Behavioral medicine. In J.D. Wright (Ed.), International encyclopedia of the social and behavioural sciences (second edition) (pp.463-469). London: Elsevier. ISBN:978-0-08-097087-5

8. Bolton D, Gillett G. The Biopsychosocial Model of Health and Disease: New Philosophical and Scientific Developments [Internet]. Cham $(\mathrm{CH})$ : Palgrave Pivot; 2019. DOI: 10.1007/978-3-030-11899-0

9. Marmot M. Social determinants of health inequalities. Lancet. 2005 Mar 19-25;365(9464):1099-104. doi: 10.1016/S0140-6736(05)71146-6.

10. Smith RC. The Biopsychosocial Revolution: Interviewing and Provider-patient Relationships Becoming Key Issues for Primary Care. J Gen Intern Med. 2002 Apr;17(4):309_ 10. doi: 10.1046/j.1525-1497.2002.20210. x.

11. Engel GL. The clinical application of the biopsychosocial model. American Journal of Psychiatry1980; 137: 5. DOI: 10.1176/ajp.137.5.535

12. Alonso Y. The biopsychosocial model in medical research: the evolution of the health concept over the last two decades. Patient Educ Couns. 2004 May;53(2):239-44. doi: 10.1016/S0738-3991(03)00146-0.

13. Farre A, Rapley T. The New Old (and Old New) Medical Model: Four Decades Navigating the Biomedical and Psychosocial Understandings of Health and Illness. Healthcare (Basel). 2017 Nov 18;5(4):88. doi: 10.3390/healthcare5040088.

14. Havelka M, Lucanin JD, Lucanin D. Biopsychosocial model--the integrated approach to health and disease. Coll Antropol. 2009 Mar;33(1):303-10.

15. Suls J, Martin R. Heart disease occurs in a biological, psychological, and social matrix: cardiac risk factors, symptom presentation, and recovery as illustrative examples. Ann Behav Med. 2011 Apr;41(2):164-73. doi: 10.1007/s12160-010-9244-y

16. Revolta C, Orrell M, Spector A. The biopsychosocial (BPS) model of dementia as a tool for clinical practice. A pilot study. Int Psychogeriatr. 2016 Jul;28(7):1079-89. doi: $10.1017 / \mathrm{S} 1041610215002379$.
17. Gagliese L, Gauthier LR, Narain N, Freedman T. Pain, aging and dementia: Towards a biopsychosocial model. Prog Neuropsychopharmacol Biol Psychiatry. 2018 Dec 20;87(Pt B):207-215. doi: 10.1016/j.pnpbp.2017.09.022.

18. Papadimitriou G. The "Biopsychosocial Model": 40 years of application in Psychiatry. Psychiatriki. 2017 AprJun;28(2):107-110. Greek, Modern, English. doi: 10.22365/jpsych.2017.282.107

19. Cohen MA. Biopsychosocial approach to the human immunodeficiency virus epidemic. A clinician's primer. General Hospital Psychiatry1990; 12(2): 98-123). DOI: 10.1016/0163-8343(90)90020-d

20. Wainwright TW, Low M. Why the biopsychosocial model needs to be the underpinning philosophy in rehabilitation pathways for patients recovering from COVID-19. Integrated Healthcare Journal2020;2(1): e000043. DOI: 10.1136/ihj-2020-000043

21. GOV.UK. Coronavirus (Covid-19) in the United Kingdom: Deaths in United Kingdom. https://coronavirus.data.gov.uk/details/deaths [Accessed on 12 May 2021]

22. GOV.UK. Coronavirus (Covid-19) in the United Kingdom: Healthcare in United Kingdom. https://coronavirus.data.gov.uk/details/healthcare [Accessed on 12 May 2021]

23. Office for National Statistics (2020) The prevalence of long Covid symptoms and Covid-19 complications. Available https://www.ons.gov.uk/news/statementsandletters/theprev alenceoflongcovidsymptomsandcovid19complications [Accessed on 25th February 2021]

24. Carr A, Smith JA, Camaradou J, Prieto-Alhambra D. Growing backlog of planned surgery due to covid-19. BMJ. 2021 Feb 9;372: n339. doi: 10.1136/bmj. n339.

25. Banks J, Xu X. The Mental Effects of the First Two Months of Lockdown and Social Distancing During the Covid-19 Pandemic in the UK. IFS Working Paper W20/16. London: Institute for Fiscal Studies; (2020).. DOI: 10.1920/wp.ifs.2020.1620

26. Mental Health Foundation (2020) Nine-Month Study Reveals Pandemic's Worsening Emotional Impacts on UK Adults. Available at: https://www.mentalhealth.org.uk/news/nine-month-studyreveals-pandemics-worsening-emotional-impacts-uk-adults [Accessed on 25th February 2021]

27. Education Endowment Foundation (2021) Interim Paper: Impact of School Closures on Attainment in Key Stage 1. Available https://educationendowmentfoundation.org.uk/covid-19resources/best-evidence-on-impact-of-school-closures-onthe-attainment-gap/ [Accessed on 25th February 2021]

28. Burgess, S., Vignoles, A. (2020) The Covid-19 Crisis and Educational Inequality. Available at: https://blogs.ucl.ac.uk/cepeo/2020/05/22/the-covid-19crisis-and-educational-inequality/ [Accessed on 25th February 2021]

29. University of Oxford (2021) Parental mental health worsens under new national COVID-19 restrictions. Available at: https://www.ox.ac.uk/news/2021-01-19parental-mental-health-worsens-under-new-national-covid19-restrictions [Accessed on 25th February 2021]

30. Hill A. 'Scarred for Life' Sage Experts Warn of Impact of Covid Policies on the Young, Guardian Online 20th October 2020. Available at: https://www.theguardian.com/uk-news/2020/oct/20/sage- 
experts-warn-of-impact-of-covid-policies-on-younggeneration-z-harm-pandemic-coronavirus [Accessed on 25th February 2021]

31. Cortina JM. What is coefficient alpha? An examination of theory and applications. Journal of applied psychology 1993); 78(1): 98. DOI: 10.1037/0021-9010.78.1.98

32. Balbinotti, MAA, Barbosa MLL. Reliability and confirmatory factorial analysis of the IMPRAFE-126 with gauchos' practitioners of physical activities. Psycho-Usf 2008;13 (1): $\quad 1-12$. DOI: $10.1590 /$ S141382712008000100002

33. Bevers K, Watts L, Kishino N, Gatchel R. The biopsychosocial model of the assessment, prevention and treatment of chronic pain. US Neurology2016;12(2): 98104. DOI: 10.17925/USN.2016.12.02.98

34. van Dijk-de Vries A, Moser A, Mertens VC, van der Linden J, van der Weijden T, van Eijk JT. The ideal of biopsychosocial chronic care: how to make it real? A qualitative study among Dutch stakeholders. BMC Fam Pract. 2012 Mar 12; 13:14. doi: 10.1186/1471-2296-13-14.

35. Bolton D. The biopsychosocial model and the new medical humanism, Archives de Philosophie 2020; 83:13-40. URL: https://www.cairn-int.info/journal-archives-dephilosophie-2020-4-page-13.htm.

DOI: 10.3917/aphi.834.0013.

36. NHS (2019) The long term plan. Available at: https://www.longtermplan.nhs.uk/wpcontent/uploads/2019/08/nhs-long-term-plan-version1.2.pdf [Accessed on 28th April 2021]

37. Curtin R, Presser S, Singer E. The effects of response rate changes on the index of consumer sentiment. Public Opin Q. 2000 Winter;64(4):413-28. doi: 10.1086/318638.
38. Moore DL, Tarnai J. (2002). Evaluating nonresponse error in mail surveys. In: Groves RM, Dillman DA, Eltinge JL, Little RJA. (eds.), Survey Nonresponse, John Wiley \& Sons, New York, pp. 197-211. ISBN: 978-0-471-39627-7

39. Singer E, van Hoewyk J, Maher MP. Experiments with incentives in telephone surveys. Public Opinion Quarterly2000; 64:171-188. DOI: 10.1086/317761

40. Groves RM, Singer E, Corning A. Leverage-saliency theory of survey participation. Public Opinion Quarterly2000; 64: 299-308. DOI: 10.1086/317990

41. Voigt LF, Koepsell TD, Daling JR. Characteristics of telephone survey respondents according to willingness to participate. American Journal of Epidemiology2003; 157:66-73. DOI: 10.1093/aje/kwf185

42. Ware Jr JE, Sherbourne CD. The MOS 36-item short-form health survey (SF-36): I. Conceptual framework and item selection. Medical care1992; 473-483. PMID: 1593914

43. Cella D, Yount S, Rothrock N, Gershon R, Cook K, Reeve B, Ader D, Fries JF, Bruce B, Rose M; PROMIS Cooperative Group. The Patient-Reported Outcomes Measurement Information System (PROMIS): progress of an NIH Roadmap cooperative group during its first two years. Med Care. 2007 May;45(5 Suppl 1): S3-S11. doi: 10.1097/01.mlr.0000258615.42478.55

44. Al-Sabbah S, Darwish A, Fares N, Barnes J, Almomani JA. Biopsychosocial factors linked with overall well-being of students and educators during the COVID-19 pandemic. Cogent Psychology2021; 8(1): 1875550 DOI:10.1080/23311908.2021.1875550

45. Althubaiti A. Information bias in health research: definition, pitfalls, and adjustment methods. J Multidiscip Healthc. 2016;9:211-217. Published 2016 May 4. DOI:10.2147/JMDH.S104807

\section{Appendix 1}

\section{Physical Health (Biological Domain) 5x5 Table}

Please rate the extent to which COVID-19 and its control measures has affected your physical health during the five phases of the pandemic

\begin{tabular}{|l|c|c|c|c|c|}
\hline pandemic & $\begin{array}{l}\text { Very positive } \\
\text { affect - improved } \\
\text { a lot }\end{array}$ & $\begin{array}{l}\text { Some positive } \\
\text { affect - improved } \\
\text { a little }\end{array}$ & No change & $\begin{array}{l}\text { Some Negative } \\
\text { affect - worsened } \\
\text { a little }\end{array}$ & $\begin{array}{l}\text { Very } \\
\text { affect }- \text { Negative } \\
\text { a lot }\end{array}$ \\
\hline $\begin{array}{l}\text { During the early } \\
\text { stages of the } \\
\text { pandemic }\end{array}$ & 0 & 0 & 0 & 0 \\
\hline $\begin{array}{l}\text { During the first } \\
\text { lockdown }\end{array}$ & 0 & 0 & 0 & 0 & 0 \\
\hline $\begin{array}{l}\text { During the easing of } \\
\text { restrictions }\end{array}$ & 0 & 0 & 0 & 0 & 0 \\
\hline $\begin{array}{l}\text { During the second } \\
\text { wave/local } \\
\text { restrictions }\end{array}$ & 0 & 0 & 0 & 0 & 0 \\
\hline $\begin{array}{l}\text { During the second } \\
\text { lockdown }\end{array}$ & 0 & 0 & 0 & 0 & 0 \\
\hline
\end{tabular}


Psychological Domain 5x5 Table

Please rate the extent to which COVID-19 and its control measures has affected you psychologically during the five phases of the pandemic

\begin{tabular}{|l|c|c|c|c|c|}
\hline & $\begin{array}{l}\text { Very positive } \\
\text { affect - improved } \\
\text { a lot }\end{array}$ & $\begin{array}{l}\text { Some positive } \\
\text { affect - improved } \\
\text { a little }\end{array}$ & No change & $\begin{array}{l}\text { Some Negative } \\
\text { affect - worsened } \\
\text { a little }\end{array}$ & $\begin{array}{l}\text { Very } \\
\text { affect }- \text { Negative } \\
\text { a lot }\end{array}$ \\
\hline $\begin{array}{l}\text { During the early } \\
\text { stages of the } \\
\text { pandemic }\end{array}$ & 0 & 0 & 0 & 0 \\
\hline $\begin{array}{l}\text { During the first } \\
\text { lockdown }\end{array}$ & 0 & 0 & 0 & 0 & 0 \\
\hline $\begin{array}{l}\text { During the easing of } \\
\text { restrictions }\end{array}$ & 0 & 0 & 0 & 0 & 0 \\
\hline $\begin{array}{l}\text { During the second } \\
\text { wave/local } \\
\text { restrictions }\end{array}$ & 0 & 0 & 0 & 0 & 0 \\
\hline $\begin{array}{l}\text { During the second } \\
\text { lockdown }\end{array}$ & 0 & 0 & 0 & 0 & 0 \\
\hline
\end{tabular}

\section{Social Domain $5 \times 5$ Table}

Please rate the extent to which COVID-19 and its control measures has affected you socially during the five phases of the pandemic (e.g. relationships, responsibilities and support for these, access to activities such as sport and culture)

\begin{tabular}{|l|c|c|c|c|c|}
\hline & $\begin{array}{l}\text { Very positive } \\
\text { affect } \begin{array}{r}\text { Some positive } \\
\text { improved a lot }\end{array}\end{array}$ & $\begin{array}{l}\text { No change } \\
\text { affect - improved } \\
\text { a little }\end{array}$ & $\begin{array}{l}\text { Some Negative } \\
\text { affect - worsened a } \\
\text { little }\end{array}$ & $\begin{array}{l}\text { Very } \\
\text { affect }- \text { Negative } \\
\text { a lot }\end{array}$ \\
\hline $\begin{array}{l}\text { During the early } \\
\text { stages of the } \\
\text { pandemic }\end{array}$ & 0 & 0 & 0 & 0 \\
\hline $\begin{array}{l}\text { During the first } \\
\text { lockdown }\end{array}$ & 0 & 0 & 0 & 0 & 0 \\
\hline $\begin{array}{l}\text { During the easing } \\
\text { of restrictions }\end{array}$ & 0 & 0 & 0 & 0 & 0 \\
\hline $\begin{array}{l}\text { During the second } \\
\text { wave/local } \\
\text { restrictions }\end{array}$ & 0 & 0 & 0 & 0 & 0 \\
\hline $\begin{array}{l}\text { During the second } \\
\text { lockdown }\end{array}$ & 0 & 0 & 0 & 0 & 0 \\
\hline
\end{tabular}

\section{Appendix 2}

To what extent do you think your physical health status is impacting on your mental health? (1-9)

To what extent do you think your social life is impacting on your physical health? (1-9)

To what extent do you think your social life is impacting on your mental health? (1-9)

Scale for each question

1 'impacting positively to a massive extent'

2

3

4

5 - 'no impact'

6

7

8

9 - 'impacting negatively to a massive extent' 